\title{
Transient method measured thermal properties of concrete with microspheres and latex based addition
}

\author{
Roman Jaskulski ${ }^{1}$, and Wojciech Kubissa ${ }^{1, *}$ \\ ${ }^{1}$ Warsaw University of Technology, Faculty of Civil Engineering, Mechanics and Petrochemistry, \\ Łukasiewicza 17, 09-402 Płock, Poland
}

\begin{abstract}
The goal of the performed research was to determine the influence of microspheres from fly ash and the latex based addition on the thermal properties of concrete. The tested additions were used in two different proportions each and they were combined with each other. As a reference two series of concrete were used: one without any addition and another with $0.2 \%$ of air entraining agent. The thermal properties were measured using transient method with ISOMET 2114 apparatus. No clear trends were observed in case of the results of the measurements of the thermal diffusivity and the volumetric heat capacity. While the results of the thermal conductivity coefficient show that both additions has a potential of lowering the thermal conductivity but they are not so efficient as air entraining agent.
\end{abstract}

\section{Introduction}

The possibilities of modifying selected concrete properties are an important direction in the development of concrete technology $[1,2]$. There are attempts to design concrete with much better thermal insulation compared to ordinary concrete $[3,4]$. Research works are carried out on the insulation performance of modified concrete walls and the effect of additives on the thermal properties of light and ordinary concrete $[5,6,7]$.

Microspheres and polymers (including latex based ones) are modern materials that enable modifying the properties of concrete, including improving its frost resistance $[8,9,10,11]$. Both polymers and microspheres modify the concrete structure tightening it $[12,13,14,15]$. However, the simultaneous use of these two materials to change the thermal properties of concrete is a new issue and as such it is not yet described in the literature.

The aim of the research presented in this article is to determine the effect of the addition of microspheres and latex based polymer on the basic thermal properties of concrete. For this purpose, the coefficient of thermal conductivity, volumetric heat capacity and thermal diffusivity by the transient method with the use of the ISOMET 2114 device were measured. The effect of both additives used independently and jointly in different propositions was determined.

\footnotetext{
* Corresponding author: wojciech.kubissa@pw.edu.pl
} 


\section{Materials and methods}

\subsection{Materials}

To test the influence of microspheres and latex based addition on thermal properties of concrete 10 concrete mixtures were prepared. Two of them served as reference. Both were prepared without adding microspheres and latex, but to one of them, marked as AE, an air entraining agent in amount of $0.2 \%$ of cement mass was added. In the other 8 concrete mixtures one or both tested additions were used in two different proportions each. Mix proportions are presented in the Table 1. The designations of the mixtures are related to the content of the additions. M stands for microspheres and L for latex based addition.

Table 1. Mix proportions of the tested concrete mixtures (in $\mathrm{kg} / \mathrm{m}^{3}$ )

\begin{tabular}{|l|c|c|c|c|c|c|c|c|c|c|}
\hline & REF & $\begin{array}{c}\text { L1 } \\
\text { M0 }\end{array}$ & $\begin{array}{c}\text { L2 } \\
\text { M0 }\end{array}$ & $\begin{array}{c}\text { L0 } \\
\text { M1 }\end{array}$ & $\begin{array}{c}\text { L0 } \\
\text { M2 }\end{array}$ & $\begin{array}{c}\text { L1 } \\
\text { M1 }\end{array}$ & $\begin{array}{c}\text { L1 } \\
\text { M2 }\end{array}$ & $\begin{array}{c}\text { L2 } \\
\text { M1 }\end{array}$ & $\begin{array}{c}\text { L2 } \\
\text { M2 }\end{array}$ & AE \\
\hline $\begin{array}{l}\text { Cement } \\
\text { CEM I 42.5R }\end{array}$ & 300 & 300 & 300 & 300 & 300 & 300 & 300 & 300 & 300 & 300 \\
\hline Water & 150.0 & 136.5 & 123.0 & 150.0 & 150.0 & 136.5 & 136.5 & 123.0 & 123.0 & 150.0 \\
\hline Sand & 356 & 352 & 348 & 337 & 318 & 333 & 314 & 329 & 310 & 356 \\
\hline $\begin{array}{l}\text { Gravel } \\
2-16 \text { mm }\end{array}$ & 1633 & 1614 & 1595 & 1544 & 1456 & 1526 & 1438 & 1507 & 1419 & 1633 \\
\hline $\begin{array}{l}\text { Latex based } \\
\text { addition }\end{array}$ & -- & 22.5 & 45.0 & -- & -- & 22.5 & 22.5 & 45.0 & 45.0 & -- \\
\hline Microspheres & -- & -- & -- & 30 & 60 & 30 & 60 & 30 & 60 & -- \\
\hline HRWR & 3 & 3 & 3 & 3 & 3 & 3 & 3 & 3 & 3 & 3 \\
\hline AEA (\% m.c.) & -- & -- & -- & -- & -- & -- & -- & -- & -- & 0.20 \\
\hline w/c & & & & & \multicolumn{7}{|c|}{0.51} & & & & \\
\hline flow [mm] & 408 & 475 & 530 & 443 & 355 & 445 & 405 & 558 & 460 & 450 \\
\hline $\begin{array}{l}\text { fc [MPa] } \\
\text { (after 28 days) }\end{array}$ & 52.8 & 47.4 & 44.5 & 52.5 & 48.0 & 43.3 & 40.9 & 40.2 & 43.7 & 52.0 \\
\hline
\end{tabular}

Portland cement CEM I 42.5R from Górażdże Cement Plant was used to prepare the mixtures. As fine aggregate quartz sand from Vistula river was used and natural gravel as coarse aggregate. As mixing water ordinary tap water was used compliant with the requirements of PN-EN 1008 [16]. In each mixture a polycarboxylate ether (PCE) based superplasticiser in amount of $1 \%$ of the cement mass was used. The $\mathrm{w} / \mathrm{c}$ ratio presented in Table 1 was calculated taking into account not only the mixing water but also mass of water contained in latex based addition (60\%) and superplasticiser (70\%). In the Table 1 two other basic properties of the concrete mixtures were presented. The results of consistency table flow test performed according to PN-EN 12350-5 [17] and the results of the compressive strength test performed after 28 days of hardening according to PN-EN 123903 [18].

Specimens for both, the thermal properties measurements and the compressive strength tests were prepared in form of $100 \mathrm{~mm}$ cubes. They were demoulded after two days of hardening and put into a water container where they were cured in temperature $20 \pm 2^{\circ} \mathrm{C}$.

\subsection{Thermal properties measurement}

Measurements of thermal properties of concrete were performed with ISOMET 2114 equipment. The measuring set consists of two probes (surface and needle) and the handheld device with alphanumeric keypad and display. It provides the dynamic measurement 
method. The measurement consists of two stages. First the specimen is heated with constant power and then it is left to cool down. Changes of the temperature of the surface of the specimen are recorded and on their basis three thermal parameters are calculated: the coefficient of thermal conductivity $\lambda$, volumetric heat capacity $C_{\rho}$ and the thermal diffusivity $a$. Knowing the bulk density of the material allows to calculate the specific heat $C_{p}$. The measurement accuracy guaranteed by the producer is $5 \%$ or $10 \%$ (depending on the measured parameter and its range), but the standard deviation calculated from the enough high number of results (over 12) is usually lower.

The measurements were performed on the $100 \mathrm{~mm}$ cube specimens that were tested in two states of saturation: fully saturated with water and dried to stable mass in $65^{\circ} \mathrm{C}$. For the test IPS 1105 surface probe was used with measurement range from 0.03 to $6.0 \mathrm{~W} / \mathrm{m} \cdot \mathrm{K}$ divided into three subranges. The probe was subsequently put on four of the cube surfaces (excluding the top and the bottom one). On each surface three measurements were made and for one concrete series two specimens were tested. As a result eighteen measurements of each thermal property were obtained for each of the series. The results were then statistically processed, the outliers were removed and rest of the results were averaged.

\section{Results and discussion}

Results of the measurements are presented in the Table 2. Values of the thermal parameters are averaged with the measurement uncertainty presented. Rough analysis of the results shows that, with exception of the thermal conductivity coefficient, it is difficult to find any clear trend in the values obtained, that would be related to the composition of the concrete mixtures. The only clear trend visible in the results is that all values obtained in case of saturated specimens are higher than those for dried ones with the same composition. Therefore, all further analysis will cover only the results of the measurements of the thermal conductivity coefficient.

Table 2. Results of the measurements of the thermal properties

\begin{tabular}{|l|c|c|c|c|c|c|}
\hline & \multicolumn{2}{|c|}{$\begin{array}{c}\text { Thermal conductivity } \\
{[\mathbf{W} / \mathbf{m} \cdot \mathbf{K}]}\end{array}$} & $\begin{array}{c}\text { Volumetric heat capacity } \\
{\left[\mathbf{M J} / \mathbf{m}^{3} \cdot \mathbf{K}\right]}\end{array}$ & \multicolumn{2}{c|}{$\begin{array}{c}\text { Thermal diffusivity } \\
{\left[\mathbf{m m}^{2} / \mathbf{h}\right]}\end{array}$} \\
\cline { 2 - 7 } & saturated & dried & saturated & dried & saturated & dried \\
\hline REF & $2.47 \pm 0.07$ & $1.82 \pm 0.03$ & $1.97 \pm 0.08$ & $1.74 \pm 0.01$ & $1.26 \pm 0.02$ & $1.04 \pm 0.01$ \\
\hline L1M0 & $2.29 \pm 0.05$ & $1.59 \pm 0.05$ & $1.83 \pm 0.04$ & $1.67 \pm 0.02$ & $1.25 \pm 0.02$ & $0.95 \pm 0.02$ \\
\hline L2M0 & $2.34 \pm 0.09$ & $1.78 \pm 0.02$ & $1.86 \pm 0.06$ & $1.75 \pm 0.00$ & $1.26 \pm 0.01$ & $1.01 \pm 0.01$ \\
\hline L0M1 & $2.53 \pm 0.03$ & $1.75 \pm 0.03$ & $1.83 \pm 0.07$ & $1.78 \pm 0.01$ & $1.36 \pm 0.04$ & $0.99 \pm 0.02$ \\
\hline LOM2 & $2.16 \pm 0.08$ & $1.56 \pm 0.04$ & $1.93 \pm 0.06$ & $1.75 \pm 0.02$ & $1.12 \pm 0.02$ & $0.89 \pm 0.02$ \\
\hline L1M1 & $2.20 \pm 0.06$ & $1.60 \pm 0.03$ & $1.84 \pm 0.03$ & $1.73 \pm 0.01$ & $1.20 \pm 0.03$ & $0.92 \pm 0.02$ \\
\hline L1M2 & $1.90 \pm 0.10$ & $1.42 \pm 0.02$ & $1.81 \pm 0.06$ & $1.66 \pm 0.01$ & $1.05 \pm 0.03$ & $0.85 \pm 0.01$ \\
\hline L2M1 & $1.97 \pm 0.05$ & $1.37 \pm 0.06$ & $1.73 \pm 0.02$ & $1.62 \pm 0.02$ & $1.14 \pm 0.03$ & $0.85 \pm 0.03$ \\
\hline L2M2 & $2.20 \pm 0.04$ & $1.41 \pm 0.05$ & $1.72 \pm 0.04$ & $1.65 \pm 0.02$ & $1.29 \pm 0.03$ & $0.85 \pm 0.02$ \\
\hline AE & $1.89 \pm 0.04$ & $1.25 \pm 0.03$ & $1.77 \pm 0.04$ & $1.62 \pm 0.02$ & $1.07 \pm 0.01$ & $0.77 \pm 0.01$ \\
\hline
\end{tabular}

For the needs of the analysis, the results were divided into six groups. The division criterion was the type of added admixture (microspheres and latex) and its dose (maximum used, half of the maximum and none). In all the groups the results were compared with results obtained in case of two reference series: REF (without any addition) and AE (with air entraining agent). 
In the case of the thermal conductivity coefficient, the following relationships of the results were noted. In case of series with no latex based addition it can be stated that adding microspheres lowered the values of the thermal conductivity, but only in case of the maximum used dose (Figure 1. a). Adding no microspheres resulted in slight decrease of thermal conductivity after adding latex based addition, but there is no clear relationship between the dose and the decrease (Figure 1. b).

a)

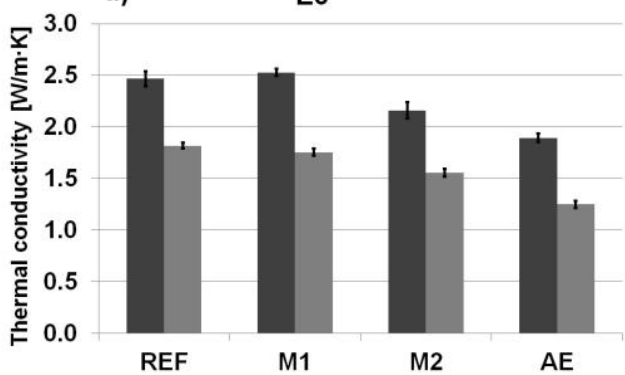

b)

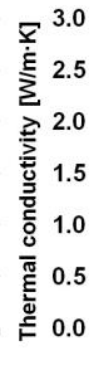
Mo

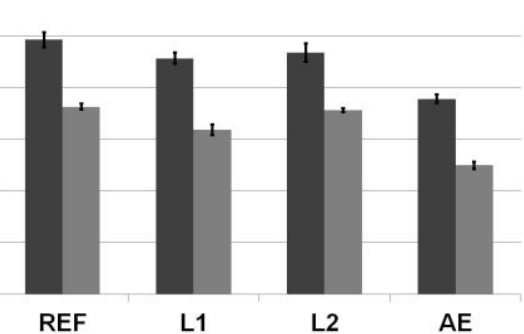

Fig. 1. Results of the measurements of the thermal conductivity coefficient for concrete series with one addition: a) microspheres, b) latex based addition

a)

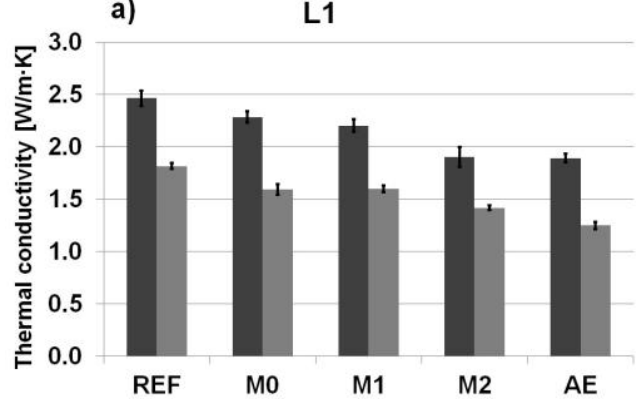

c)

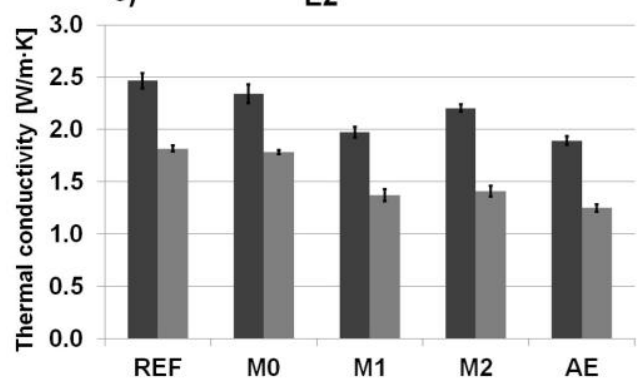

b)
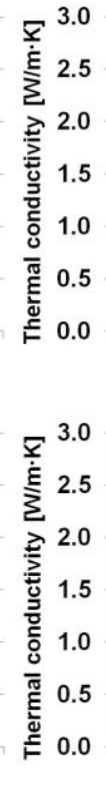

d)
(1)

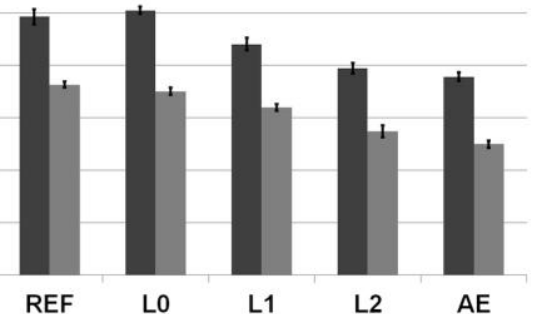
M2

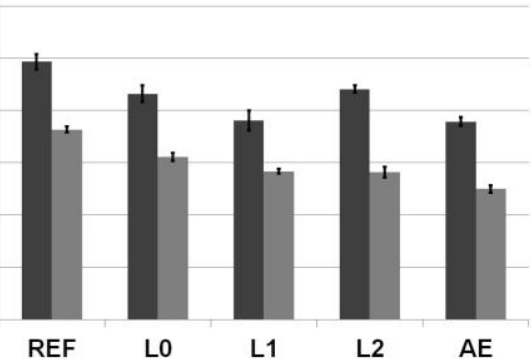

Fig. 2. Results of the measurements of the thermal conductivity coefficient for concrete series with different doses of the two additions: a) latex based addition (half of the maximum dose), b) microspheres (half of the maximum dose) c) latex based addition (the maximum dose), d) microspheres (the maximum dose)

If series with half of the maximum used doses of one of the additions are concerned, the tendency of decrease of the thermal conductivity with the increase of the dose of the other addition is visible. And this tendency is more clear in Figure 2. b (increasing the dose of latex based addition) than in Figure 2. a (increasing the dose of microspheres). The results obtained for the series with the maximum used dose of one addition and increasing dose of the other do not show any clear trend, but in both cases (Figure 2. c and d) the minimum value of the thermal conductivity for saturated specimens was obtained, when the other 
addition was used in the half of the maximum dose used. For the dried specimens there is not such a clear extreme.

In the Figure 3 results of the measurements of the thermal conductivity coefficient of all tested concrete series in both states of saturation are presented. The series are distinguished with use of the symbols related to designations of mixtures in Table 1. The axes with thermal conductivity values are shortened to better expose the differences among the series. It can be easily seen, that in both cases the lowest values of the thermal conductivity were obtained for the reference concrete series with the air entrainment addition.
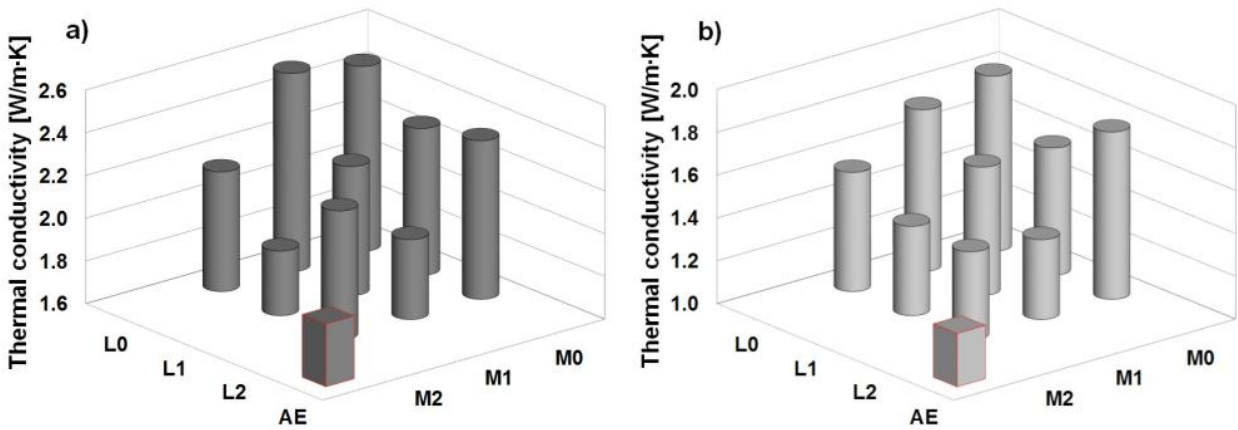

Fig. 3. Results of the measurements of the thermal conductivity coefficient: a) concrete specimens fully saturated with water, b) concrete specimens dried in $65^{\circ} \mathrm{C}$ to constant mass

In case of the specimens fully saturated with water, the obtained values of the thermal conductivity coefficient in almost all cases fit between the values obtained for the reference series REF and AE. Only the L0M1 series achieved a $2.5 \%$ higher value of the thermal conductivity than the REF series $(2.53 \mathrm{~W} / \mathrm{m} \cdot \mathrm{K}$ to $2.47 \mathrm{~W} / \mathrm{m} \cdot \mathrm{K})$. However, this difference falls within the range of measurement uncertainty and can be considered as insignificant. The lowest values of thermal conductivity in the series with the addition of microspheres or latex based addition were obtained in the case of the L1M2 series $(1.90 \mathrm{~W} / \mathrm{m} \cdot \mathrm{K})$ and $\mathrm{L} 2 \mathrm{M} 1$ $(1.97 \mathrm{~W} / \mathrm{m} \cdot \mathrm{K})$.

In the case of the dried specimens, all obtained values of the thermal conductivity coefficient fit between the values obtained for the reference series. The lowest thermal conductivity value in the series with the addition of microspheres or latex based addition was obtained in the case of the L2M1 series $(1.37 \mathrm{~W} / \mathrm{m} \cdot \mathrm{K})$, and the largest in the case of the L2M0 series $(1.78 \mathrm{~W} / \mathrm{m} \cdot \mathrm{K})$.

It is noticeable the general trend in concrete series with one addition, regardless of the state of saturation of concrete, that increasing the amount of latex based addition increases the value of thermal conductivity, and increasing the amount of microspheres decreases it. This may be related to the tendency for latex to form in concrete, with its larger dose, segments of a continuous structure that conducts the heat somewhat better. Microspheres, on the other hand, increase the amount of air in the concrete, which is characterized by low thermal conductivity and, after exceeding a certain threshold, clearly reduces the thermal conductivity of the concrete. A similar effect is caused by the addition of air entraining agent, which proved to be the most effective in lowering the thermal conductivity coefficient of concrete.

\section{Conclusions}

The obtained results allowed for the following conclusions:

- Both latex based addition and microspheres allow to reduce the thermal conductivity of concrete. 
- Increasing the latex based addition dose without using microspheres leads to an increase in the thermal conductivity value, and increasing the content of microspheres without using latex based addition reduces it.

- The combined use of latex and microspheres with at least one of the additives in the maximum amount $\left(45 \mathrm{~kg} / \mathrm{m}^{3}\right.$ latex or $60 \mathrm{~kg} / \mathrm{m}^{3}$ microspheres) resulted in a decrease in thermal conductivity by at least $20 \%$ regardless of the saturation of the concrete.

- The most effective addition reducing the thermal conductivity coefficient of concrete in the analysed series was the air entraining agent used in the amount of $0.2 \%$ of the mass of the cement, and its advantage was particularly evident in the case of testing specimens dried at $65^{\circ} \mathrm{C}$ to stable mass.

The authors wish to thank Mr. Patryk Tomczak for his help in preparing specimens for the tests.

\section{References}

1. M. A. Glinicki, Prz. Bud. 12, 24-30 (2007)

2. L. Czarnecki and W. Kurdowski, Budownictwo, Technol. Archit. 37, 50-55 (2007)

3. M. Y. J. Liu, U. J. Alengaram, M. Z. Jumaat, and K. H. Mo, Energy Build. 72, 238245 (Elsevier B.V., 2014)

4. Q. L. Yu, P. Spiesz, and H. J. H. Brouwers, Cem. Concr. Compos. 44, 17-29 (2013)

5. L. Evangelisti, C. Guattari, P. Gori, and R. De Lieto Vollaro, Sustain. 7, 8, 10388 10398 (2015)

6. J. J. del Coz Díaz, P. J. García Nieto, C. Betegón Biempica, and M. B. Prendes Gero, Appl. Therm. Eng. 27, 8-9, 1445-1456 (2007)

7. A. Tarameshloo, E. N. Kani, and A. Allahverdi, Can. J. Civ. Eng. 44, 11, 893-898 (2017)

8. W. Wang, L. Zhao, Y. Liu, and Z. Li, Mag. Concr. Res. 66, 10, 492-504 (2014)

9. V. Semenov and T. Rozovskaya, Procedia Eng. 153, 623-629 (2016)

10. S. Laustsen, M. T. Hasholt, and O. M. Jensen, Mater. Struct. Constr. 48, 1-2, 357-368 (2015)

11. M. T. Hasholt, O. M. Jensen, and S. Laustsen, Adv. Civ. Eng. Mater. 4, 1, 237-256 (2015)

12. A. K. H. Kwan and J. J. Chen, Powder Technol. 234, 19-25 (Elsevier B.V., 2013)

13. J. J. Chen, P. L. Ng, L. G. Li, and A. K. H. Kwan, Procedia Eng. 172, 165-171 (2017)

14. Y. Liu, Y. F. Chen, W. Wang, and Z. Li, Constr. Build. Mater. 104, 116-125 (Elsevier Ltd, 2016)

15. J. Wawrzeńczyk, A. Molendowska, and A. Kłak, Procedia Eng. 161, 79-84 (2016)

16. PN-EN 1008, Mixing water for concrete. Specification for sampling, testing and assessing the suitability of water, including water recovered from processes in the concrete industry, as mixing water for concrete, in Polish Stand. (2004)

17. PN-EN 12350-5, Testing fresh concrete. Part 5: Flow table test, in Polish Stand. (2011)

18. PN-EN 12390-3, Testing hardened concrete. Compressive strength of test specimens, in Polish Stand. (2001) 